\title{
Nutritional Status of Hospitalized Stroke Patients: Assessment by Body Mass Index and Subjective Global Assessment Method
}

\author{
Gloria Kartika, ${ }^{1}$ Lisda Amalia, ${ }^{2}$ Gaga Irawan Nugraha ${ }^{3}$ \\ ${ }^{1}$ Faculty of Medicine Universitas Padjadjaran, ${ }^{2}$ Department of Neurology Faculty of Medicine \\ Universitas Padjadjaran/Dr. Hasan Sadikin General Hospital Bandung, ${ }^{3}$ Department of Public \\ Health Faculty of Medicine Universitas Padjadjaran
}

\begin{abstract}
Background: Stroke is a disease with a high mortality rate and common cause of disability. Nutritional factors are strongly associated with this disease. Malnutrition in hospitalized patients increases the incidence of complications, prolonged the length of stay and also the cost of hospitalization. Furthermore, nutritional status of stroke patients can deteriorate during hospitalization. The prevalence of malnutrition in hospitalized stroke patients is about $6 \%$ to $62 \%$. The objective of this study was to identify the nutritional status of hospitalized stroke patient.
\end{abstract}

Methods: This was a descriptive cross-sectional study. Population of the study was hospitalized stroke patients at Neurology Ward, Kemuning Building Dr. Hasan Sadikin General Hospital Bandung, Indonesia from August until October 2014 who meet the inclusion criteria. Nutritional status was measured objectively using Body Mass Index (BMI) and subjectively using Subjective Global Assessment (SGA) method. The collected data were processed using frequency tabulation and percentage.

Results: Twenty six hospitalized stroke patients were included in this study. The hospitalized patients with normal BMI were about 12 people (46.15\%), 8 people were overweight (30.77\%), 4 people were undernourished (15.39\%) and 2 people (7.69\%) were obese. According to SGA measurement, approximately 18 people (69.22\%) were moderately malnourished, and as much as 4 people (15.39\%) were in good nutrition, whereas 4 people (15.39\%) were severely malnourished.

Conclusions: Majority of the hospitalized stroke patients has normal BMI and moderately malnourished based on SGA.

Keywords: Body Mass Index, nutritional status, stroke, Subjective Global Assessment

\section{Introduction}

Stroke is a disease with high mortality rate and the most frequent cause of disability. Stroke was ranked as the third killer disease in the United States of America. ${ }^{1}$ Moreover, the survival rate of this disease is also low. According to statistical data from University Hospital Network New Jersey, only 10\% of stroke patients were able to recover completely while $25 \%$ had minor disability, 40 had moderate disability while $15 \%$ died shortly. ${ }^{2}$ Indonesia has the highest number of death among stroke patients followed by Philippines, Singapore, Brunei, Malaysia and Thailand. $^{3}$

The nutritional status of stroke patient tends to decrease during hospitalization. As such, the prevalence of malnutrition among stroke patients is about 6-62\%. ${ }^{4}$ This is not very surprising as the nutritional status of most patients were already bad prior to stroke. Increase in both metabolic demands and catabolic stress also tends to deteriorate nutritional status. Malnutrition in hospitalized patients leads to many complications such as prolong hospital stay and increased in hospital cost. ${ }^{5,6}$ One of the best ways to assess nutritional status is by using Body Mass Index (BMI) for objective evaluation of nutritional status and Subjective Global Assessment (SGA) for subjective evaluation of nutritional status. ${ }^{6}$ Subjective evaluation of nutritional status by SGA is an alternative evaluation that is practical, simple and valid by using clinical

Correspondence: Gloria Kartika, Faculty of Medicine, Universitas Padjadjaran, Jalan Raya Bandung-Sumedang Km.21, Jatinangor, Sumedang, Indonesia, Phone: +62 81261715107 Email: gloria_kartika@yahoo.com 
evaluation to identify patients with risk of malnutrition or even malnourished patients. 5,7 The objective of this study was to identify the nutritional status of hospitalized stroke patients.

\section{Methods}

The study was based on observational descriptive with cross-sectional design. This study had been approved by Ethical Committee of Hasan Sadikin General Hospital, Bandung Number 8794/Diklit/VIII/14. The subjects of this study were stroke patients in the Neurology Ward of Kemuning Building, Dr. Hasan Sadikin General Hospital, Bandung, Indonesia from August to October 2014. Total sampling was used in this study.

The inclusion criteria for this study were patients presented with primary or reccurent both infarct stroke and hemorrhagic stroke who were hospitalized at the Neurology Ward of Kemuning Building, Hasan Sadikin General Hospital between August and October 2014. Patients' or any family member were asked to sign informed consent prior to participating in this study. On the other hand, stroke patient with diabetes mellitus, aphasia, dementia, decreased consciousness and unstable vital signs were excluded from the study.

Variables measured was BMI and SGA. Anthropometry measurement (height and body weight), anamnesis, and physical examination for SGA assessment was obtained. Body weight measurement for hospitalized patient was conducted using bed scales SECA 985 type, meanwhile body height was estimated using recumbent length method and measured using a measure tape ABN type. The recumbent length measurement is a common method in measuring bedridden patients and is the most accurate method to estimate the patients' height.8 BMI then calculated using the formula below:

BMI = Body weight $(\mathrm{kg}) /$ Height2 (m)

Table 1 BMI Category

\begin{tabular}{lc}
\hline \multicolumn{1}{c}{ Category } & BMI (kg/m2) \\
\hline Undernutrition & $<18,5$ \\
Normal & $18,5-24,9$ \\
Overweight & $25-29.9$ \\
Obese & $\geq 30$ \\
\hline
\end{tabular}

Table 2 Classification of SGA

\begin{tabular}{cc}
\hline Category & Explaination \\
\hline A & Good nutrition \\
B & Moderate malnutrition \\
C & Severe malnutrition \\
\hline
\end{tabular}

BMI obtained was then classified into the following categories based on WHO.

Subjective Global Assessment involved anamnesis about weight loss for the last 6 months expressed in both kilograms and proportionate loss, changes in food intake duration and degree (starvation, hypocaloric liquid, full liquid diet, suboptimal solid diet), gastrointestinal complaints for at least in the last 2 weeks (nausea, vomiting, diarrhea, anorexia), changes in functional capacity (suboptimum, ambulatory or bed rest), primary diagnosis and metabolic demands, physical examinations was conducted to find loss of subcutaneous fat, atrophy of muscles, edema, and ascites. ${ }^{5}$ Loss of subcutaneous fat and atrophy of muscles were evaluated subjectively by the examiner and was categorized as normal, slightly decrease, moderate, severe. ${ }^{7}$ Patients were then categorized according to the degree of nutritional status as follows:

Patient was categorized as moderate malnutrition when there was a decrease in $5 \%$ body weight with no subsequent increase, decreased of food intake, and light loss of subcutaneous tissue. Patient was categorized as severe malnutrition when there was a severe loss of subcutaneous tissue, atrophy of muscles and edema. ${ }^{7}$

\section{Results}

Between August to October 2014, 45 stroke patients were hospitalized whereas only 26 patients fulfilled all the inclusion and exclusion criteria. Table 3 showed the demographic characteristic of subjects included in this study.

The prevalence of female patients with stroke was higher compared to male patients with a ratio of male patients to female patients of 1:1.36 (Table 3). Most stroke patients were between 43 years old to 78 years old with the average age of 59.8 years old. The patients' data were collected from day two until the 16th day of hospitalization with an average of 4 days.

The difference in nutritional status assessment between patients at the onset of hospitalization was then matched with the 
Table 3 Characteristics of subjects

\begin{tabular}{lcc}
\hline & $\begin{array}{c}\text { Total Patients } \\
\text { (n=26) }\end{array}$ & $\begin{array}{c}\text { Percentage } \\
\text { (\%) }\end{array}$ \\
\hline Gender & 11 & 42.31 \\
male & 15 & 57.69 \\
female & & \\
Age group (years old) & 3 & 11.54 \\
40-49 & 12 & 46.15 \\
$50-59$ & 7 & 26.92 \\
$60-69$ & 4 & 15.39 \\
$\geq 70$ & & \\
Type of stroke & 13 & 50.00 \\
Infarct & 13 & 50.00 \\
Hemorrhagic & & \\
Onset stroke & 13 & 50,00 \\
First stroke & 13 & 50.00 \\
Repeated stroke & & \\
Onset of hospitalization until measurement (days) & & 80.77 \\
$0-5$ & 21 & 15.38 \\
6 -10 & 4 & 3.85 \\
$>10$ & 1 & \\
\hline
\end{tabular}

stability of the patient's clinical condition at the moment. Most of patients can be measured on less than five days of hospitalization. Body Mass Index of the patients showed in Table 4.

Majority of the patient had normal BMI $(46.15 \%)$ with least obese patients $(7.69 \%)$ (Table 4). In addition, SGA method was also used to evaluate the nutritional status of the patients. The characteristics of the parameter for SGA evaluation was shown in Table 5.

Based on Table 5, it could be concluded that most of the patients experienced loss of body weight. Gastrointestinal effect referred to nausea, vomiting, diarrhea, and anorexia. Physical examination was carried out to identify any sign of malnutrition such as loss of subcutaneous fat, atrophy of muscles, edema at lower extremities and ascites and this study discovered that most of the patients had not has any physical changes regarding the SGA standards.

Based on the SGA evaluation, majority of the patient experienced moderate malnutrition while the percentage number of patients with good nutrition and severe malnutrition were equal.

Table 4 Nutritional status based on BMI

\begin{tabular}{lcc}
\hline & Total patients $(\mathbf{n = 2 6})$ & Percentage (\%) \\
\hline Underweight & 4 & 15.39 \\
Normal & 12 & 46.15 \\
Overweight & 8 & 30.77 \\
Obese & 2 & 7.69 \\
\hline
\end{tabular}


Table 5 Characteristics of patients based on SGA

Total patients $(n=26)$

Percentage (\%)

\begin{tabular}{lcc}
\hline Decrease in body weight & 9 & 34.62 \\
No & 17 & 65.38 \\
Yes & & \\
Nasogastric tube usage & 13 & 50.00 \\
$\quad$ Without nasogastric tube & 13 & 50.00 \\
With nasogastric tube & & \\
Gastrointestinal complaints & 21 & 80.77 \\
Yes & 5 & 19.23 \\
No & & \\
Changes in functional capacity & 0 & 0.00 \\
No & 7 & 26.92 \\
Suboptimal / ambulatory & 19 & 73.08 \\
Bedridden & & \\
Physical examination & 19 & 73.08 \\
No changes & 7 & 26.92 \\
There are changes & & \\
\hline
\end{tabular}

\section{Discussion}

This study discovered that almost half of the patients had overweight or obese. A study conducted in Hospital Adam Malik showed a strong relationship between obesity and stroke $(\mathrm{p}<0,013) .{ }^{10}$ On top of that, it has been shown that increase in BMI during middleage increased the risk of getting total stroke and ischemic stroke but not hemorrhaging stroke. ${ }^{10}$ The study showed similar result with a study carried out at Neurology Department of Klinikum Mannheim and Klinikum Heidelberg in Germany that obesity measured by BMI or waist circumference showed significant relationship towards risk of getting stroke and TIA. ${ }^{11}$ Obesity is usually related with hyperlipidemia, hypercholesterolemia and hypertriglyceridemia which lead to atherosclerosis that ultimately result in ischemic stroke. Besides that, hypertension in obese people is an important risk factor for hemorrhaging stroke which usually caused by increased in cardiac output and plasma volume. ${ }^{10}$

Based on the nutritional status evaluated by SGA, many patients had moderate malnutrition. Malnutrition occurs due to various reasons such as increased in metabolism caused by stroke and decreased in gastrointestinal function. On top of that, decreased in gastrointestinal function could be due to disturbances in the oral, pharynx, and esophageal function which often manifested as dysphagia. ${ }^{4}$ Dysphagia is defined as difficulty in swallowing and can be followed by painful swallowing. In a previous study, the prevalence of dysphagia in stroke is as high as $52.6 \%{ }^{9}$

Table 6 Nutritional status based on SGA

\begin{tabular}{lcc}
\hline & Total patients $(\mathbf{n = 2 6 )}$ & Percentage (\%) \\
\hline Good nutrition & 4 & 15.39 \\
Moderate malnutrition & 18 & 69.22 \\
Severe malnutrition & 4 & 15.39 \\
\hline
\end{tabular}


Dysphagia often leads to aspiration in $20-25 \%$ patient and is strongly related with increased in mortally and pneumonia. In addition, there is a significant relationship between dysphagia and malnutrition. ${ }^{13}$ Dysphagia often leads to loss of body weight due to decreased in food intake. Besides that, dysphagia often causes discomfort during swallowing which ultimately causes the patient's to lose his or her appetite which eventually lead to malnutrition in hospitalized patients. To increase the food intake in patient with dysphagia, nasogastric tube is often used. In this study, 13 people or precisely $50 \%$ of the patients had dysphagia and used a nasogastric tube for food intake. Out of 13 patients, 10 have moderate malnutrition while the other had severe malnutrition.

Stroke patients also experienced loss of body weight due to loss of appetite caused by depression, cognitive deficit, upper extremities paralysis, visual and cognitive changes like hemianopsia and apraxia. ${ }^{4}$ In addition, malnutrition in stroke patient usually is caused by the inability of the body of the stroke patient to tolerate enteral nutrition due to decrease in intestinal motility and weak gastrointestinal muscles tones. This condition leads to inadequate food digestion which tend to decrease the gastrointestinal function of the patient.

Nutritional status evaluation based on BMI showed that most of the patient has normal nutritional status contradictory to SGA. As such, BMI only takes into account the energy usage of the patient while SGA is more comprehensive in evaluating the patients. BMI measurement does not take into account the loss of body weight, changes in diet, gastrointestinal effects such as nausea, vomiting, diarrhea, anorexia, metabolic stress, changes in functional capacity and changes in the patients physic. Planas et al. ${ }^{7}$ showed anthropometry and SGA evaluation were not similar in nature and SGA itself was a better method to assess nutritional status. In certain scenario, patients might be categorized as obese and as they progress, they often experienced about 10\% of loss in body weight accompanied with gastrointestinal symptoms and present with edema during BMI measurement. This is why it is crucial to have sound understanding in nutritional status of the patient and BMI must be calculated to evaluate the nutritional status and SGA comparison. ${ }^{12}$

There were several limitations in this study such as limited timeframe, which lead to smaller sample size. In addition, there were no earlier study conducted in Hasan Sadikin General
Hospital regarding this matter. Furthermore, this study did not cover the nutritional status of the patients prior to hospitalization, other diseases present and complications which might affect the nutritional status.

In conclusion, most of the hospitalized stroke patients have normal BMI. However, SGA evaluation indicates that they have moderate malnutrition. This is an alarming issue as the high prevalence of moderate malnutrition could progress to severe malnutrition.

Further study is needed to identify the factors that lead to malnutrition. This study can also be used as a reference for further research to determine the relationship between malnutrition and period of hospitalization.

Besides that, the author also recommends that nutritional assessment should be routinely carried out to evaluate hospitalized patients and to assess patients' response in term of nutritional status. Education about proper nutrition and meal time for stroke patient should be given to the family. This is important to help the patient reaches the ideal bodyweight to prevent comorbidity. On top of that, education about how to prevent recurrent stroke should be given to both patient and the family. Finally, nutritional status should be evaluated during follow-up at polyclinic to assess the effectiveness of nutritional therapy for home-care in stroke patient.

\section{References}

1. Yuniadi Y. Intervensi pada stroke nonhemoragik. KARIDN. 2010;31(3):153-5.

2. Newmark UH. Stroke statistic. New Jersey. 2013 [cited 2014 March 1]. Available from: http://www.uhnj.org/stroke/stats.htm.

3. Cintya YS, Susila S. Gambaran faktor risiko dan tipe stroke pada pasien rawat Inap di bagian penyakit dalam RSUD Kabupaten Solok Selatan periode 1 Januari 201031 Juni 2012. Jurnal Kesehatan Andalas. 2013;2(2):57-61.

4. Foley N, Richardson M, Bhogal S, Speechley M. Nutritional interventions following stroke. EBRSR [Evidence-Based Review of Stroke Rehabilitation. 2013;16:1-37.

5. Keith JN. Bedside nutrition assessment past, present, and future: a review of the subjective global assessment. Nutr Clin Pract. 2008;23(4):410-416

6. da Silva HV, Santos S, Silva N, Ribeiro F, Josua L, Moreira A. Nutritional assessment associated with length of inpatients hospital stay. Nutr Hosp. 2012;27(2):5427. 
7. Froehlich-Grobe K, Nary DE, Van Sciver A, Lee J, Little TD. Measuring height without a stadiometer empirical investigation of four height estimates among wheelchair users. Am J Phys Med Rehabil. 2011;90(8):65866.

8. Crary MA, Carnaby-Mann GD, Miller L, Antonios N, and Silliman S. Dysphagia and nutritional status at the time of hospital admission for ischemic stroke. J Stroke Cerebrovas Dis. 2006;15(4):164-71.

9. Ophine L. Hubungan antara obesitas dengan stroke pada pasien rawat inap di bagian ilmu penyakit saraf FK-USU/ RSUP H. Adam Malik Medan. Medan: Universitas Sumatera Utara; 2010.
10. Winter Y, Linseisen J, Lanczik O, Ringleb PA, Hebebrand J, Back T. Contribution of obesity and abdominal fat mass to risk of stroke and transient ischemic attacks. J Am Heart Assoc. 2008;39:3145-51.

11. Theresia KB, Amir A, Hendrayati, Ayu SD. Studi komparasi metode penilaian status gizi indeks massa tubuh dan subjective global assessment (SGA) pasien rawat inap di Rumah Sakit DR Wahidin Sudirohusodo Makassar. J GIZI PANGAN. 2011;11(1):710

12. Edmiaston J, Connor LT, Loehr L, Nassief A.. Validation of a dysphagia screening tool in acute stroke patients. Am J Crit Care. 2010;19(4):357-6. 